\title{
Introduction to Selected Contributions from the 49th US Rock Mechanics/Geomechanics Symposium Held in San Francisco, California from 28 June to 1 July, 2015
}

\author{
Joseph Morris ${ }^{1,2} \cdot$ Alvin Chan $^{3} \cdot$ Russell Detwiler $^{4}$. \\ Greg Hasenfus $^{5} \cdot$ Haiying Huang ${ }^{6}$ - Marisela Sanchez-Nagel ${ }^{7}$
}

Published online: 25 October 2016

(c) Springer-Verlag Wien 2016

This special issue of Rock Mechanics and Rock Engineering contains papers that are a representative sample of contributions from the 49th US Rock Mechanics/Geomechanics Symposium. This multidisciplinary international annual meeting of the American Rock Mechanics Association (ARMA) is a focal event for the Rock Mechanics and Geomechanics community, bringing together professionals and students from civil, geological, mining, geophysical and petroleum engineering.

The manuscripts presented address a range of topics from geotechnical classification to hydraulic fracturing.
The papers presented include field relevant study, laboratory experiments and investigations empowered by high performance computing. The papers contained in this special issue were selected by members of the Organizing Committee of the 49th US Rock Mechanics/Geomechanics Symposium based on the quality of the technical content of the symposium papers. All papers were expanded and rewritten, then re-reviewed for this special issue.

Joseph Morris

morris50@1lnl.gov

Schlumberger-Doll Research Center, Cambridge, MA, USA

2 Lawrence Livermore National Laboratory, Livermore, CA, USA

3 Shell International, New Orleans, LA, USA

4 University of California, Irvine, CA, USA

5 Consol Energy Inc.,, Canonsburg, PA, USA

6 Georgia Institute of Technology, Atlanta, GA, USA

7 OilField Geomechanics, Houston, TX, USA 